\title{
Ulas-balik
}

\section{Status taksonomi iktiofauna endemik perairan tawar Sulawesi}

\author{
(Taxonomical status of endemic freshwater ichthyofauna of Sulawesi) \\ Renny Kurnia Hadiaty \\ Laboratorium Iktiologi, Bidang Zoologi, Puslit Biologi-LIPI \\ Jl. Raya Bogor Km 46, Cibinong 16911 \\ Diterima: 25 Mei 2018; Disetujui: 5 Juni 2018
}

\begin{abstract}
Abstrak
Perairan tawar Pulau Sulawesi merupakan habitat beragam iktiofauna endemik Indonesia yang tidak dijumpai di bagian manapun di dunia ini. Dari perairan tawar pulau ini telah dideskripsi 68 spesies ikan endemik dari tujuh familia, tergolong dalam empat ordo. Ke tujuh familia tersebut adalah Adrianichthyiidae (19 spesies, dua genera), Telmatherinidae (16 spesies, empat genera), Zenarchopteridae (15 spesies, tiga genera), Gobiidae (14 spesies, empat genera), Anguillidae (satu spesies, satu genus), Eleotridae dua spesies, dua genera), dan Terapontidae (satu spesies, satu genus). Sebagian besar spesies endemik di P. Sulawesi hidup di perairan danau (45 spesies atau 66,2\%), 23 spesies hidup di perairan sungai. Spesies pertama yang dideskripsi dari P. Sulawesi adalah Glossogobius celebius oleh Valenciennes tahun 1837 , spesimen tipenya disimpan di Museum Paris. Delapan spesies ditemukan pada abad 19, sampai sebelum kemerdekaan Indonesia telah ditemukan 29 spesies, setelah merdeka ditemukan 39 spesies di P. Sulawesi. Di awal penemuan spesies baru, spesimen tipe disimpan di museum luar negeri, namun sejak tahun 1990 dipelopori oleh Dr. Maurice Kottelat spesimen tipe disimpan di Museum Zoologicum Bogoriense (MZB), Bidang Zoologi, Pusat Penelitian Biologi. Sampai saat ini spesimen tipe iktiofauna dari P. Sulawesi disimpan di 27 museum dari 11 negara di dunia, terbanyak di Amerika (8), Jerman (6), Swiss (3), Australia, dan Belanda (2), sedangkan di Austria, Jepang, Perancis, Singapura, Inggris, dan Indonesia masing-masing satu museum.
\end{abstract}

Kata penting: endemik, iktiofauna, museum, Sulawesi, tipe

\begin{abstract}
The freshwaters of Sulawesi are the habitat of numerous endemic Indonesian ichthyofauna that are not found anywhere else in the world. About 68 endemic fish species described from the Sulawesi's freshwaters, it consisted of seven familia of four order. The seven familia are Adrianichthyiidae (19 spesies, two genera), Telmatherinidae (16 spesies four gen), Zenarchopteridae (15 spesies, three gen), Gobiidae (14 spesies., empat gen), Anguillidae (one spesies, one gen), Eleotridae (two spesies, two gen), Terapontidae (one spesies, one gen). Most of the Sulawesi's endemic ichthyofauna inhabit in lakes (45 spp., about 66.2\%), 23 spp. lives in the rivers. The Sulawesi's first species was Glossogobius celebius described by Valenciennes in 1837, the type spesimen deposited in Paris Museum. Eight species described in 19 century, up to the year of Indonesian independence 29 spesies described, after that 39 spesies of endemic ichthyofauna described from Sulawesi' freshwater. The earlier description the type specimen deposited in the foreign museums, but in 1990 Dr. Maurice Kottelat pioneered to deposited the type specimen in Museum Zoologicum Bogoriense (MZB), Zoologi Division of Research Center for Biology. So far, the type specimens of Sulawesi freshwater ichthyofauna deposited in 27 museums of 11 countries in the world, the most museums were in United Stated of America ( 8 museums), Germany (6 museums), Schwitzerland (3 museums), Australia and Netherlands (2 museums), while the others (Austria, Japan, Singapore, United Kingdom and Indonesia) each country with one museums respectively.
\end{abstract}

Keywords: endemic, ichthyofauna, museums, Sulawesi, type

\section{Pendahuluan}

Pulau Sulawesi mempunyai riwayat geografi menarik. Terbentuknya pulau ini telah dikaji oleh para ahli biogeografi (Hall 1996 1998, Holloway \& Hall 1998, Lohman et al. 2011).

\footnotetext{
$\triangle$ Penulis korespondensi Alamat surel: rani_hadiaty@yahoo.com
}

Visualisasi garis pantai, sistem sungai, dan durasi ketinggian air laut disampaikan oleh Voris (2000). Fauna di P. Sulawesi paling istimewa dibanding seluruh wilayah Indonesia lainnya; dari 127 spesies mammalia asli pulau ini, 79 spesies diantaranya endemik. Babirusa, Babyrousa babyrussa merupakan fauna pertama yang di- 
deskripsikan oleh peneliti Eropa, fauna ini dideskripsi oleh Piso tahun 1658 (Whitten et al. 2012). Keistimewaan Sulawesi telah mengundang para peneliti dunia untuk meneliti sejarah geologi, biogeologi, biogeokimiawi, juga fauna-flora yang ada di pulau ini (Clements et. al. 2006, Crabbe \& Smith 2005, Crowe et al. 2008, 2011; Clumsee et al. 2011, Gray et al. 2008, Haffner et al. 2001, Herder et al. 2006 a b, Kawakatsu \& Mitchell 1989, Koch 2011, Moss \& Wilson 1998, Rintelen et al. 2012, 2014, Schwarzer et al. 2008, Siebert 2005)

Semua ikan asli Sulawesi adalah spesies air payau yang toleran terhadap air tawar. Beberapa di antaranya terbatas hidup di danau, sementara sidat beruaya antara danau dan lautan. Banyak spesies telah diintroduksi secara sengaja atau tidak sengaja, yaitu Channa striata dan Anabas testudineus, keduanya mendominasi perikanan air tawar di Sulawesi (Whitten et al. 2012).

Penelitian iktiofauna di P. Sulawesi telah dipublikasikan di beberapa media publikasi, prosiding, jurnal ataupun bagian dari buku (Cerwenka et al. 2012, Hadiaty 2007, 2012; Hadiaty \& Wirjoatmodjo 2002, Hadiaty et al. 2004, Herder \& Chapuis 2010, Herder et al. 2006a b, 2012, Miesen et al. 2015, Pfaender et al. 2011, 2014, 2016; Schwarzer et al. 2008, Stelbrink et al. 2014, Vari \& Hadiaty 2012, Wirjoatmodjo et al. 2003, Yamahira et al. 2016).

Tulisan ini mengungkapkan informasi mengenai iktiofauna endemik di P. Sulawesi yaitu status taksonomi, era penemuan dan authornya serta deposit spesimen tipe di museummuseum dunia. Diharapkan, tulisan ini dapat memberikan informasi bagi para peneliti atau mahasiswa yang sedang meneliti iktiofauna di P. Sulawesi, terutama tentang nama sahih, nama author penemu, dan tahun publikasi, serta ditam- bahkan pula informasi museum tempat disimpannya spesimen tipe ikan asli Indonesia tersebut. Spesimen tipe untuk spesies baru yang dideskripsi di atas tahun 1990, dideposit di Museum Zoologicum Bogoriense (MZB), Bidang Zoologi, Pusat Penelitian Biologi - Lembaga Ilmu Pengetahuan Indonesia (Gambar 1). Para taksonom Indonesia dan asing saat menemukan spesies baru, akan mendeskripsi dan mempublikasikan jenis baru tersebut akan menghubungi kurator MZB untuk memesan nomor bagi spesimen tipe (holotipe, bila spesimen cukup banyak juga paratipe).

Informasi iktiofauna endemik diperoleh dari berbagai publikasi yang telah terbit di berbagai jurnal internasional yaitu Aurich (1935a b, 1938), Ahl (1936), Bleeker 1860, Boulenger 1897, Brembach (1982, 1991), Collete (1995), Cuvier \& Valenciennes (1837), Eschmeyer \& Fong (2018), Eschemeyer et al. (2018), Froese \& Pauly (2018), Hadiaty (2007, 2012), Hadiaty \& Wirjoatmodjo (2002), Hadiaty et al. (2004), Herder \& Chapuis (2010), Herder et al. (2012), Hoese \& Kottelat (2005), Hoese et al. (2015), Huylebrouck et al. (2012, 2014), Kottelat (1990 a b c, 1991), Ladiges (1972), Larson (2001), Larson \& Kottelat (1992), Larson et al. 2014, Meisner \& Louie (2000), Mokodongan et al. (2014, 2018), Nielsen et al. (2009), Parenti (2008), Parenti \& Louie (1998), Parenti \& Soeroto (2004), Parenti \& Hadiaty (2010), Parenti et al. (2013), Popta (1905, 1922), van der Laan et al. (2018), Vogt (1978), Weber (1894, 1913), dan Weber \& de Beaufort (1922).

Informasi yang diperoleh lalu diolah datanya, dikelompokkan jenis-jenis berdasarkan perairan (danau, sungai atau keduanya), wilayah persebarannya berdasar provinsi, era penemuan, dan juga penyimpanan spesimen tipe di museum di dunia. 


\section{Iktiofauna endemik}

Perairan tawar P. Sulawesi merupakan habitat 68 spesies iktiofauna endemik, yang tidak dijumpai di tempat lain di dunia. Iktiofauna endemik tersebut termasuk dalam empat ordo dari tujuh familia (Tabel 1). Diteliti dari habitatnya, sebagian besar iktiofauna endemik tersebut hidup di perairan danau (54 spesies), di perairan sungai 13 spesies, namun ada pula yang dijumpai hidup di danau dan di sungai (11 spesies).

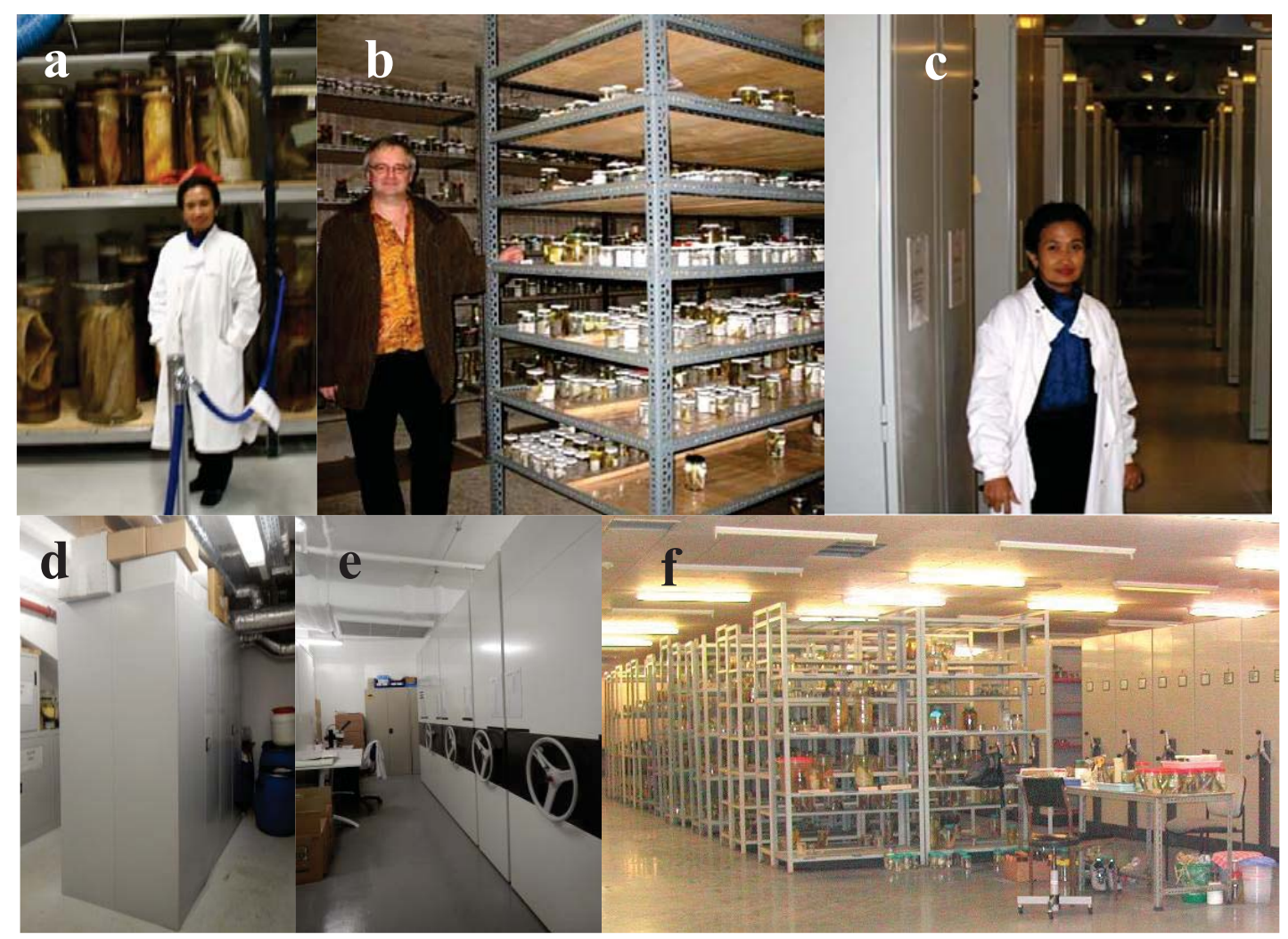

Gambar 1 Ruang koleksi di beberapa museum dunia: a. The Natural History Museum, London (The NHM), b. Colection of Kottelat, Swiss (CMK) c. The NHM, d. Zoologisches Furschungmuseum of Alexander Koenig, Bonn (ZFMK), e. The Zoological Reference Collection, Singapura (ZRC); f. Museum Zoologicum Bogoriense-LIPI, Cibinong (MZB)

Tabel 1. Iktiofauna endemik dari perairan tawar Pulau Sulawesi

\begin{tabular}{|c|c|c|c|c|c|}
\hline No & Ordo & No & Famili & No & Species, Author \& Tahun Publikasi \\
\hline 1 & Anguilliformes & 1 & Anguillidae & 1 & Anguilla celebesensis Kaup 1856 \\
\hline \multirow[t]{13}{*}{2} & Atheriniformes & 2 & Telmatherinidae & 2 & Marosatherina ladigesi (Ahl 1936) \\
\hline & & & & 3 & Paratherina cyanea Aurich 1935 \\
\hline & & & & 4 & Paratherina labiosa Aurich 1935 \\
\hline & & & & 5 & Paratherina striata Aurich 1935 \\
\hline & & & & 6 & Paratherina wolterecki Aurich 1935 \\
\hline & & & & 7 & Telmatherina abendanoni Weber 1913 \\
\hline & & & & 8 & Telmatherina antoniae Kottelat 1991 \\
\hline & & & & 9 & Telmatherina bonti Weber \& de Beaufort 1922 \\
\hline & & & & 10 & Telmatherina celebensis Boulenger 1897 \\
\hline & & & & 11 & Telmatherina obscura Kottelat 1991 \\
\hline & & & & 12 & Telmatherina opudi Kottelat 1991 \\
\hline & & & & 13 & Telmatherina prognatha Kottelat 1991 \\
\hline & & & & 14 & Telmatherina sarasinorum Kottelat 1991 \\
\hline
\end{tabular}


Adrianichthyiidae
Telmatherina wahjui Kottelat 1991.

Tominanga aurea Kottelat 1990

Tominanga sanguicauda Kottelat 1990

Adrianichthys kruyti Weber 1913

Adrianichthys oophorus (Kottelat 1990)

Adrianichthys poptae (Weber \& de Beaufort 1922)

Adrianichthys roseni Parenti \& Soeroto 2004

Oryzias asinua Parenti, Hadiaty, Lumbantobing \& Herder 2013

Oryzias bonneorum Parenti 2008

Oryzias celebensis (Weber 1894)

Oryzias eversi Herder, Hadiaty \& Nolte 2012

Oryzias hadiatyae Herder \& Chapuis 2010

Oryzias marmoratus (Aurich 1935)

Oryzias matanensis (Aurich 1935)

Oryzias nebulosus Parenti \& Soeroto 2004

Oryzias nigrimas Kottelat 1990

Oryzias orthognathus Kottelat 1990

Oryzias profundicola Kottelat 1990

Oryzias sarasinorum (Popta 1905).

Oryzias soerotoi Mokodongan, Tanaka \& Yamahira 2014

Oryzias wolasi Parenti, Hadiaty, Lumbantobing \& Herder 2013.

Oryzias woworae Parenti \& Hadiaty 2010

Dermogenys orientalis (Weber 1894).

Dermogenys vogti Brembach 1982.

Nomorhamphus brembachi Vogt 1978

Nomorhamphus celebensis Weber \& de Beaufort 1922

Nomorhamphus ebrardtii (Popta 1912)

Nomorhamphus hageni (Popta 1912)

Nomorhamphus kolonodalensis Meisner \& Louie 2000

Nomorhamphus lanceolatus Huylebrouck, Hadiaty \& Herder 2014

Nomorhamphus liemi Vogt 1978

Nomorhamphus megarrhamphus (Brembach 1982)

Nomorhamphus rex Huylebrouck, Hadiaty \& Herder 2012

Nomorhamphus sagittarius Huylebrouck, Hadiaty \& Herder 2014.

Nomorhamphus towoetii Ladiges 1972

Nomorhamphus weberi (Boulenger 1897).

Tondanichthys kottelati Collette 1995

Lagusia micracanthus (Bleeker 1860)

Bostrychus microphthalmus Hoese \& Kottelat 2005

Belobranchus segura Keith, Hadiaty \& Lord 2012

Glossogobius celebius (Valenciennes 1837)

Glossogobius flavipinnis (Aurich 1938)

Glossogobius intermedius Aurich 1938

Glossogobius mahalonensis Hoese, Hadiaty \& Herder 2015

Glossogobius matanensis (Weber 1913)

Lentipes mekonggaensis Keith \& Hadiaty 2014

Mugilogobius adeia Larson \& Kottelat 1992

Mugilogobius amadi (Weber 1913)

Mugilogobius hitam Larson, Geiger, Hadiaty \& Herder 2014

Mugilogobius latifrons (Boulenger 1897)

Mugilogobius lepidotus Larson 2001

Mugilogobius rexi Larson 2001

Mugilogobius sarasinorum (Boulenger 1897)

Redigobius penango (Popta 1922) 
Di P. Sulawesi terdapat tiga danau (D.) purba, yaitu D. Poso, D. Matano, dan D. Towuti (Gambar 2). Dua danau terakhir merupakan sistem dari lima danau yang saling berhubungan dan sering disebut sebagai Danau-danau Malili (Malili Lakes) (Gambar 2) yang terdiri atas D.
Matano yang outletnya mengalir ke D. Mahalona, D. Lantoa, dan D. Masapi outletnya mengalir ke D. Towuti. Danau Towuti yang luasnya mencapai $561 \mathrm{~km}^{2}$ merupakan danau terluas ke dua di Indonesia, sedangkan yang pertama adalah Danau Toba yang luasnya mencapai $1.130 \mathrm{~km}^{2}$.

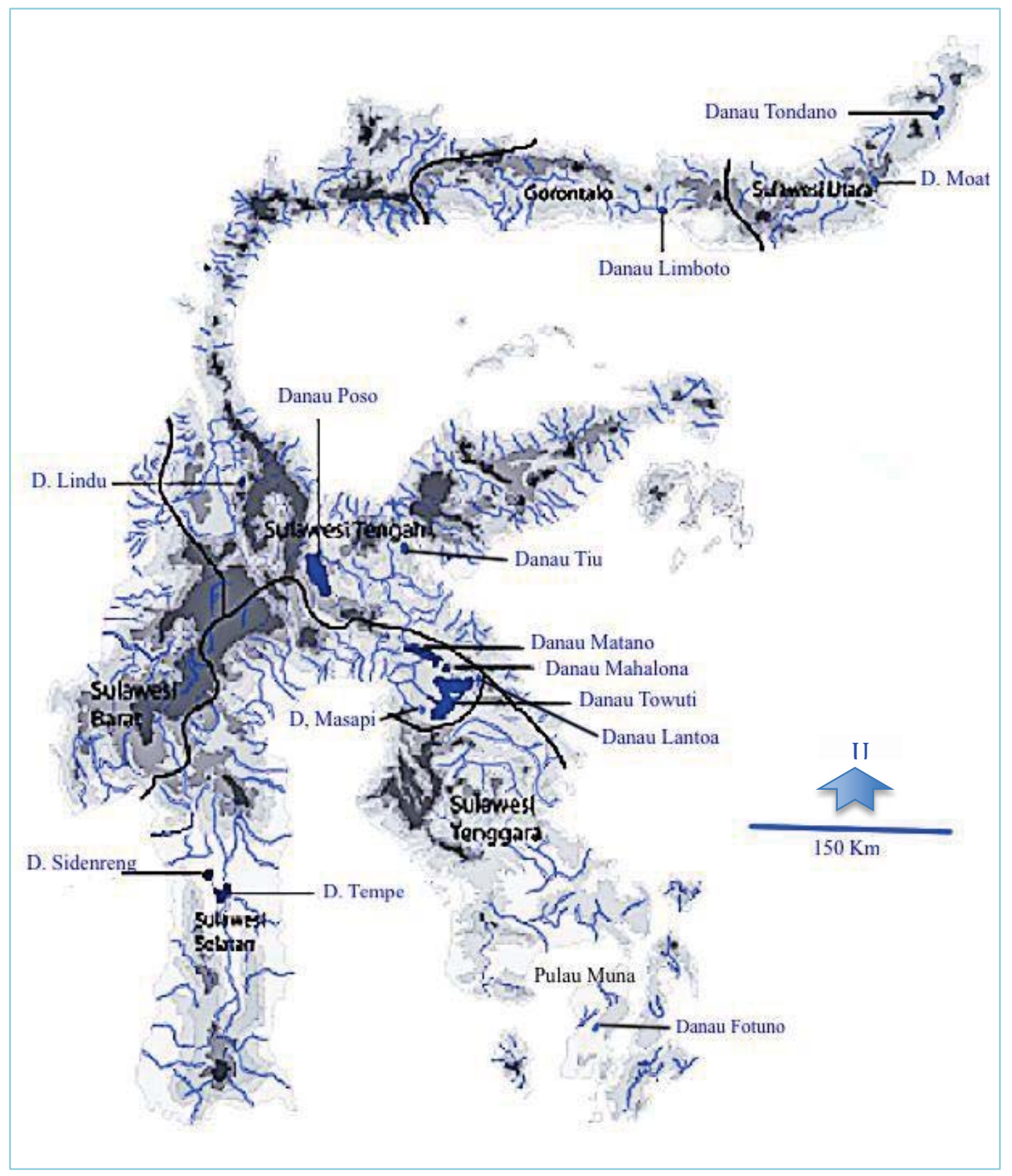

Gambar 2. Danau-danau di Pulau Sulawesi (peta modifikasi dari Miesen et al. 2015) 
Tidak hanya iktiofauna endemik hidup di danau-danau Malili, banyak taksa fauna lain yang endemik, sehingga ke lima danau ini sangat menarik bagi para peneliti asing yang berdatangan dan meneliti fauna endemik yang hidup di dalamnya (Rintelen \& Glaubrecht 2003, Koch 2011, Kawakatsu \& Mitchell 1989, Rintelen \& Glaubrecht 2003, Rintelen et al. 2007, Lang \& Vogel 2006, Sabo et al. 2008, Zitzler \& Cai 2006)

Dari jumlah spesies, iktiofauna endemik terbanyak hidup di D. Towuti (17 spesies), diikuti oleh D. Matano, dihuni 12 spesies endemik, D. Poso dihuni 10 spesies, D. Mahalona 9 spesies, D. Lindu dan D. Tondano masing-masing dua spesies, sedangkan D. Lantoa dan D. Masapi dihuni satu spesies ikan endemik (Gambar 3). Total jumlah spesies dari ke lima danau tersebut adalah 40 spesies atau $58,9 \%$ dari total iktiofauna endemik pulau ini. Iktiofauna yang hidup di perairan tawar sungai, gua dan danau di Provinsi Sulawesi Tenggara ada 12 spesies, sedangkan di Provinsi Sulawesi Selatan ada 11 spesies. Satu spesies yang dideskripsi dari perairan tawar P. Sulawesi yaitu Anguilla celebensensis oleh Kaup
(1856), tidak diketahui persis lokasinya karena hanya ditulis Sulawesi.

Dari jumlah spesies iktiofauna yang telah dideskripsi tersebut, terlihat jelas bahwa perairan tawar di Provinsi Sulawesi Selatan, Sulawesi Tenggara, dan Sulawesi Tengah yang terbanyak spesies endemiknya, sedangkan di Provinsi Sulawesi Utara hanya dua yaitu Tondanichthys kottelati dan Anguila celebesensis. Tampaknya tidak banyak penelitian taksonomi ikan dilakukan di wilayah utara pulau ini.

\section{Status taksonomi}

Iktiofauna endemik perairan tawar P. Sulawesi yang statusnya sahih berjumlah 68 spesies dari 16 genera yaitu Marosatherina, Paratherina, Telmatherina, Tominanga, Adrianichthys, Oryzias, Dermogenys, Nomorhamphus, Tondanichthys, Lagusia, Bostrychus, Belobranchus, Glossogobius, Lentipes, Mugilogobius, Anguilla, dan Redigobius. Spesies endemik terbanyak di P. Sulawesi adalah Oryzias (15), diikuti Nomorhamphus (12), Telmatherina (9), Mugilogobius (7), dan Glossogobius (5), sedangkan ke 11 genera lainnya jumlah spesiesnya kurang dari 5 (Gambar 4a).

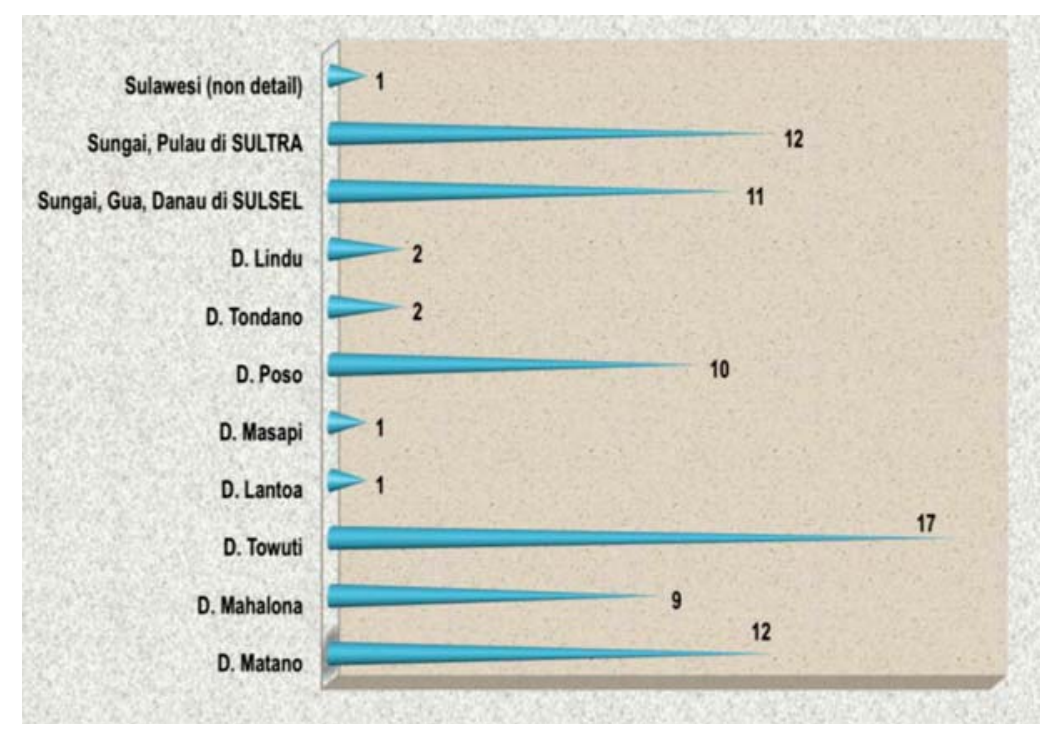

Gambar 3. Habitat dan jumlah spesies iktiofauna endemik di perairan tawar Pulau Sulawesi 

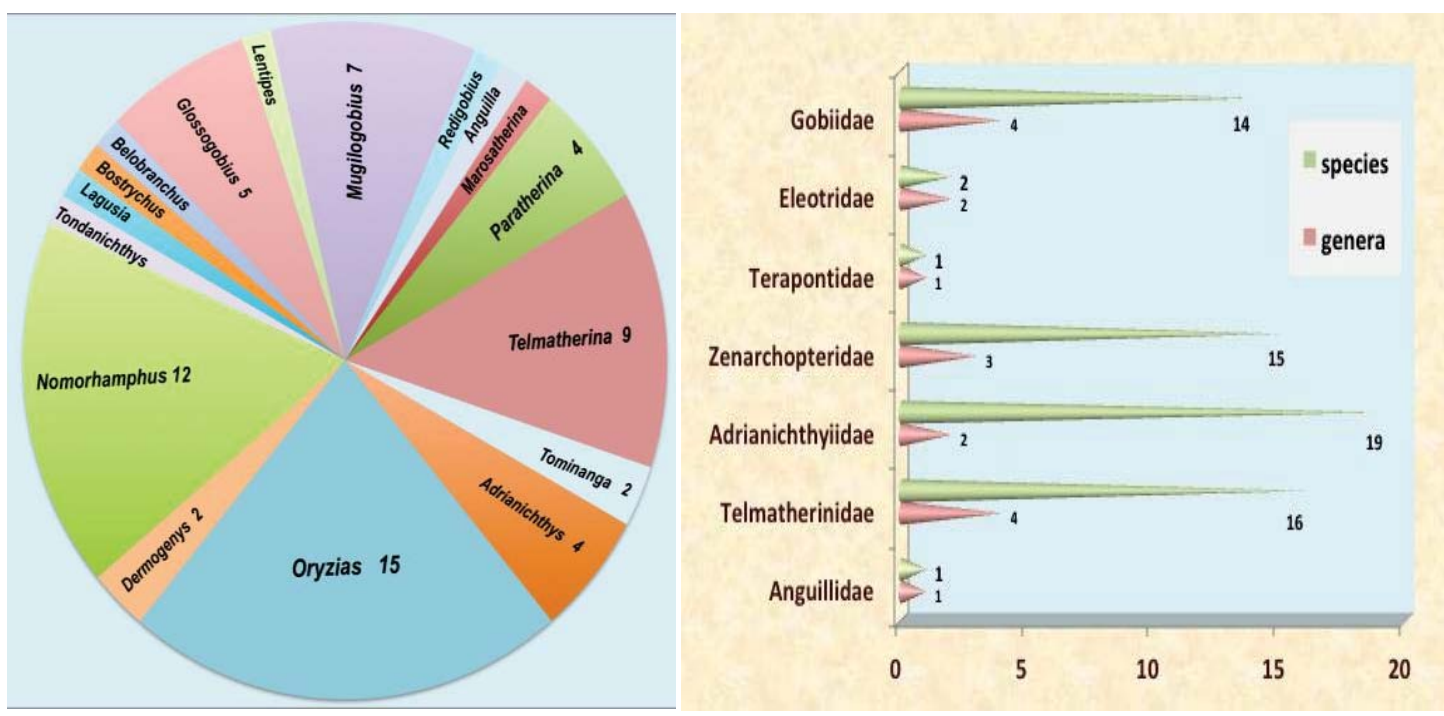

Gambar 4. Iktiofauna endemik diperairan tawar Sulawesi: a. Genera dan jumlah spesies iktiofauna endemik di P. Sulawesi, b. Familia, jumlah genera dan spesies.

Enam diantaranya merupakan genera endemik karena genus tersebut tidak dijumpai satu spesies pun di luar pulau P. Sulawesi, genera yang sangat special tersebut adalah Marosatherina, Paratherina, Telmatherina, Tominanga, Tondanichthys, dan Lagusia.

Jumlah total spesies dari ke lima danaudanau Malili tersebut, 40 spesies $(58,9 \%)$ dari total iktiofauna endemik dari P. Sulawesi, dari tiga genera yaitu Paratherina, Telmatherina, dan Tominanga. Di samping itu ada juga spesies endemik yang genusnya dijumpai di perairan lain yaitu Oryzias (15 spesies), Dermogenys (2 spesies), Glossogobius (5 spesies), Mugilogobius (7 spesies), sedangkan genus lainnya Anguilla, Bostrychus, Belobranchus, Lentipes, dan Redigobius masing-masing terwakili satu spesies.

Beberapa genera iktiofauna endemik namanya tetap sahih sejak pertama dideskripsi, contohnya Paratherina, Telmatherina, Tominanga, dan Tondanichthys, sehingga penulisan author (yang mendeskripsi) spesies tersebut ditu- lis langsung di belakang nama spesies tanpa tanda kurung (Tabel 1). Beberapa spesies setelah dipelajari lebih lanjut ternyata termasuk genus yang berbeda, maka dalam penulisannya nama author dan tahun publikasi ditulis dalam kurung (Tabel 2).

Ada beberapa spesies yang dideskripsi dari perairan tawar P. Sulawesi statusnya menjadi sinonim setelah dipelajari oleh Kottelat (2013), diantaranya:

1. Nomorhamphus ravnaki australe Brembach 1991 menjadi sinonim Nomorhamphus brembachi Vogt 1978

2. Dermogenys montanus Brembach 1982 jadi sinonim Dermogenys orientalis (Weber 1894)

3. Nomorhamphus ravnaki Brembach 1991 jadi sinonim Nomorhamphus brembachi Vogt 1978

4. Nomorhamphus sanussii Brembach 1991 menjadi sinonim Nomorhamphus brembachi Vogt 1978 
Tabel 2. Penulisan nama spesies sahih, namun berganti nama generanya

\begin{tabular}{cll}
\hline No & \multicolumn{1}{c}{ Nama spesies saat dipublikasi } & \multicolumn{1}{c}{ Nama sahih spesies, author, dan tahun publikasi } \\
\hline 1 & Telmatherina ladigesi Ahl 1936 & Marosatherina ladigesi (Ahl 1936) \\
2 & Xenopoecilus oophorus Kottelat 1990 & Adrianichthys oophorus (Kottelat 1990) \\
3 & Xenopoecilus poptae Weber \& de Beaufort 1922 & Adrianichthys poptae (Weber \& de Beaufort 1922) \\
4 & Haplochilus celebensis Weber 1894 & Oryzias celebensis (Weber 1894) \\
5 & Apocheilus marmoratus Aurich 1935 & Oryzias marmoratus (Aurich 1935) \\
6 & Apocheilus matanensis Aurich 1935 & Oryzias matanensis (Aurich 1935) \\
7 & Hemirhamphus orientalis Weber 1894 & Dermogenys orientalis (Weber 1894). \\
8 & Hemirhamphus ebrardtii Popta 1912 & Nomorhamphus ebrardtii (Popta 1912) \\
9 & Hemirhamphus hageni Popta 1912 & Nomorhamphus hageni (Popta 1912) \\
10 & Dermogenys megarrhamphus Brembach 1982 & Nomorhamphus megarrhamphus (Brembach 1982) \\
11 & Hemirhamphus weberi Boulenger 1897 & Nomorhamphus weberi (Boulenger 1897). \\
12 & Datnia micracanthus Bleeker 1860 & Lagusia micracanthus (Bleeker 1860 \\
13 & Gobius celebius Valenciennes 1837 & Glossogobius celebius (Valenciennes 1837) \\
14 & Stupidogobius flavipinnis Aurich 1938 & Glossogobius flavipinnis (Aurich 1938) \\
15 & Gobius matanensis Weber 1913 & Glossogobius matanensis (Weber 1913) \\
16 & Gobius amadi Weber 1913 & Mugilogobius amadi (Weber 1913) \\
17 & Gobius latifrons Boulenger 1897 & Mugilogobius latifrons (Boulenger 1897) \\
18 & Gobius sarasinorum Boulenger 1897 & Mugilogobius sarasinorum (Boulenger 1897) \\
19 & Pseudogobius penango Popta 1922 & Redigobius penango (Popta 1922)
\end{tabular}

Era penemuan spesies endemik dan para penemunya

Penemuan spesies iktiofauna endemik perairan tawar P. Sulawesi dibagi menjadi tiga era yaitu: era sebelum tahun 1900, era pramerdeka (1905-1938), dan era pascamerdeka (1972-2015). Di era sebelum tahun 1900, telah dideskripsi sembilan spesies iktiofauna air tawar. Namanama besar seperti Valenciennes, Bleeker, Weber, Boulenger \& Kaup yang mendeskripsi spesies-spesies tersebut. Di era pramerdeka lima orang taksonomis yaitu Ahl, Aurich, de Beaufort, Popta, dan Weber telah mendeskripsi 20 spesies iktiofauna. Di era pascamerdeka 24 taksonomis telah mendeskripsi 39 spesies iktiofauna dari perairan tawar P. Sulawesi (Gambar 5a,b).

Spesies pertama yang dideskripsi dari $\mathrm{P}$. Sulawesi adalah Glossogobius celebius, dideskripsi oleh Valenciennes tahun 1837, nama lokasi tidak disebutkan terinci, hanya dikatakan dari Sulawesi. Taksonomist yang mendeskripsi 68 spesies perairan tawar P. Sulawesi terdiri atas 21 orang author pertama dan 13 orang author pendamping (Gambar 5b). Taksonomis yang terbanyak mendeskripsi adalah Kottelat dengan 12 spesies, diikuti oleh Weber 9 spesies, Aurich 8 spesies, dan Parenti 6 spesies. Taksonomis lainnya mendeskripsi kurang dari 5 spesies.

Suatu bukti perhatian author terhadap spesies yang dideksripsinya ditunjukkan oleh Kottelat. Pada saat mendeskripsi iktiofauna dari Malili Lakes sebagai pakar dia mengetahui ketentuan bahwa Spesimen Tipe (Holotipe dan Paratipe) harus dideposit di negara asal spesies tersebut. Saat mempublikasikan 12 spesies iktiofauna dari P. Sulawesi, telah ditetapkan bahwa spesimen tipe akan disimpan di LIPI, namun mengingat saat itu koneksi belum sebaik dan secepat sekarang, dalam publikasi disebutkan LIPI dengan nomor berurutan (Kottelat 1990a b,1991). Spesimen belum diserahkan ke LIPI mengingat saat itu kantor Laboratorium 


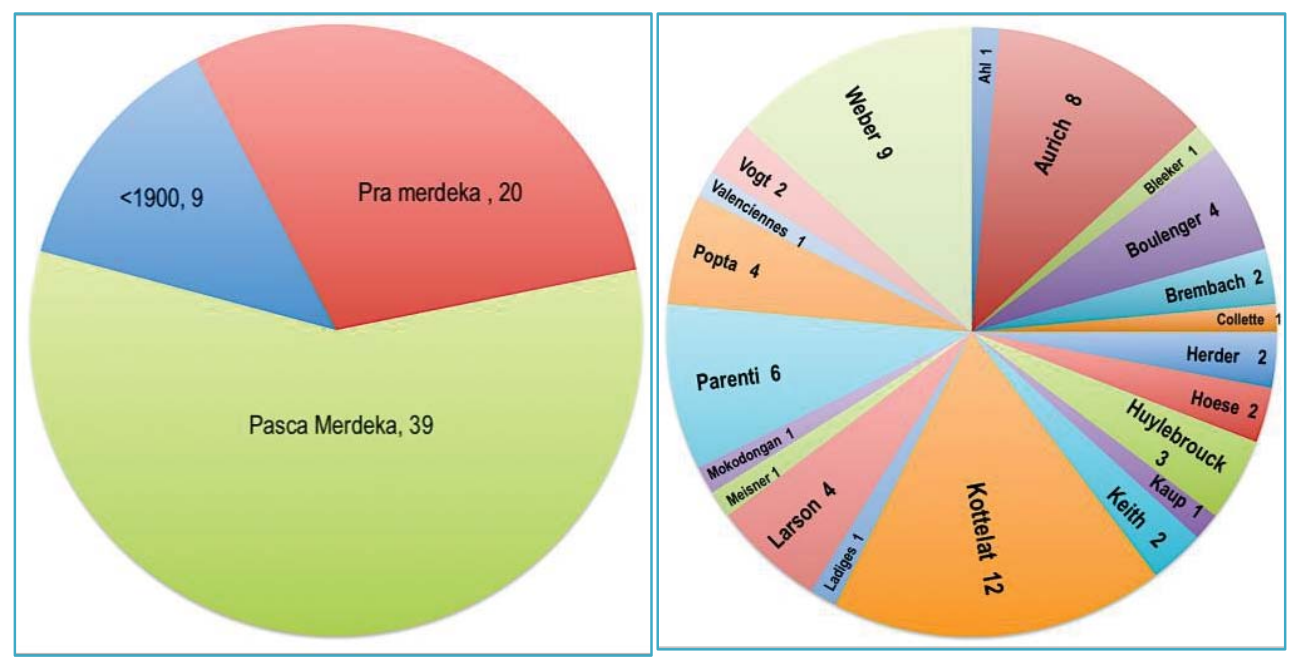

Gambar 5. Penemuan iktiofauna perairan air tawar P. Sulawesi: a. Penemuan berdasarkan era, b. author dan jumlah spesies yang dideskripsinya.

Iktiologi, Balai Penelitian dan Pengembangan Zoologi, Pusat Penelitian \& Pengembangan Biologi masih berkantor di area Kebun Raya Bogor. Kondisi penyimpanan spesimen di Museum Zoologicum Bogoriense (MZB) belum memenuhi standar menyebabkan Kottelat menunda memberikan spesimen tipe tersebut.

Periode 1997 LIPI menerima gedung baru di Cibinong dari hasil kerjasama Japan International Cooperation Agency JICA (yang membangun gedung dan mengisi peralatan di dalamnya) dan World Bank (memberi fasilitas pelatihan kepada para kurator dan collection manager mempelajari cara pengananan koleksi di beberapa museum dunia). Kottelat merupakan salah satu konsultan dari World Bank dan beberapa kali mengunjungi fasilitas baru tersebut, sehingga beliau melihat langsung fasilitas MZB sudah memenuhi kriteria standar museum penyimpanan spesimen fauna. Pada saat penulis mendapat kesempatan untuk mengunjungi enam museum di Eropa tahun 2006 dengan dukungan dana dari The All Catfish Species Inventory (The ACSI) yang dipimpin oleh Prof. Larry M Page, Ph.D, penulis mengunjungi Collection of Maurice Kottelat (CMK) di Cornol, Swiss. Spesimen tipe tersebut diberikan oleh Dr. Maurice Kottelat untuk dibawa kembali ke Indonesia dan disimpan di koleksi MZB.

Pada saat ini bila peneliti akan mendeskripsi spesies baru, mereka akan menghubungi Kurator di Laboratorium Iktiologi guna mendapatkan nomor MZB untuk spesimen tipe maupun voucher spesimen lainnya. Dengan demikian saat publikasi jenis baru tersebut holotipenya sudah menyandang nomor MZB.

\section{Deposit tipe di museum}

Spesimen tipe dari 68 spesies iktiofauna perairan tawar Sulawesi disimpan di 26 museum dari 11 negara di dunia. Di Amerika Serikat dan di Jerman, ada enam museum yang menyimpan spesimen tipe tersebut, di Swiss dan Australia tiga museum, di Belanda dua museum, sedangkan Austria, Jepang, Perancis, Singapura, Inggris dan Indonesia sendiri satu museum (Gambar 6 dan Tabel 3). 


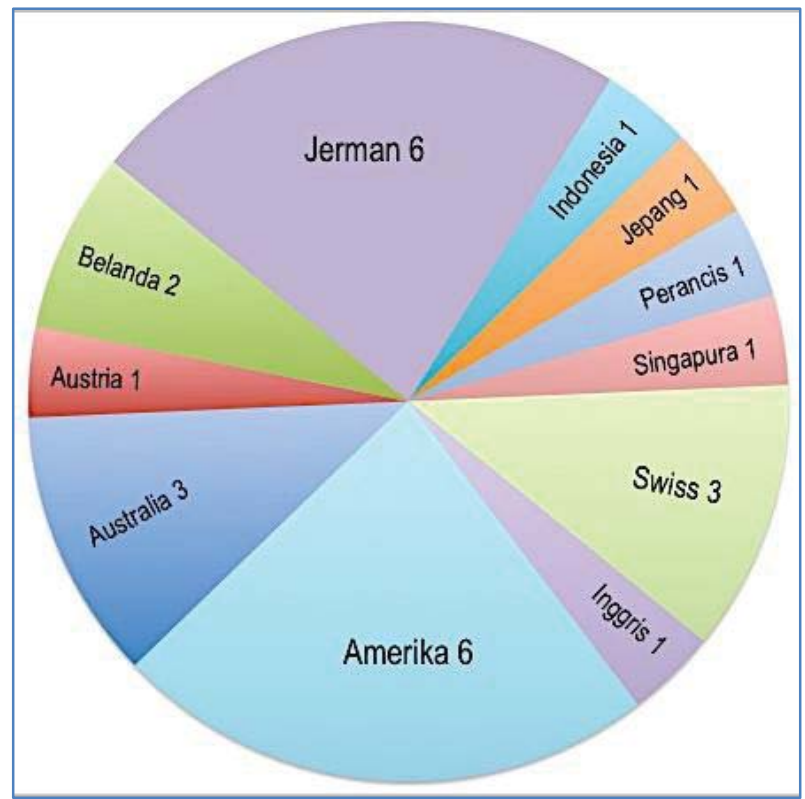

Gambar 6. Nama negara dan jumlah museum yang menyimpan spesimen tipe dari iktiofauna perairan tawar dari P. Sulawesi

Tabel 3. Nama museum dan negara yang menyimpan spesimen tipe iktiofauna perairan tawar Sulawesi

\begin{tabular}{|c|c|c|c|}
\hline No & Nama Museum & Singkatan & Negara \\
\hline 1 & $\begin{array}{l}\text { Museums and Art Galleries of the Northern Territory, Northern Territory } \\
\text { Museum of Arts \& Sciences, Ichthyology, Darwin, Australia }\end{array}$ & NTM & Australia \\
\hline 2 & $\begin{array}{l}\text { Queensland Museum, Centre for Biodiversity, Fishes, Brisbane, } \\
\text { Queensland, Australia. }\end{array}$ & QM & Australia \\
\hline 3 & Australian Museum, Sidney, New South Wales, Australia & AMS & Austalia \\
\hline 4 & Naturalis - National Natuurhistorisch Museum, Leiden, Netherlands. & RMNH & Belanda \\
\hline 5 & $\begin{array}{l}\text { Originally: Universiteit van Amsterdam, Faculty of Science, Zoölogisch } \\
\text { Museum, Amsterdam, The Netherlands. }\end{array}$ & ZMA & Belanda \\
\hline 6 & $\begin{array}{l}\text { National Museum of Nature and Science, Zoology Department, Division of } \\
\text { Fishes, Tsukuba, Japan. Preferred style is NSMT-P } 12345\end{array}$ & NSMT-P & Jepang \\
\hline 7 & Museum Zoologicum Bogoriense, Cibinong, Indonesia & MZB & Indonesia \\
\hline 8 & Staatliches Naturhistorisches Museum, Braunschweig, Germany. & NMB & Jerman \\
\hline 9 & $\begin{array}{l}\text { Senckenberg Forschungsinstitut und Naturmuseum, Abteilung Marine } \\
\text { Zoologie, Sektion Ichthyologie, Frankfurt am Main, Hessen, Germany. }\end{array}$ & SMF & Jerman \\
\hline 10 & $\begin{array}{l}\text { Zoologisches Forschungsmuseum Alexander König, Abteilung Wirbeltiere, } \\
\text { Ichthyologie, Bonn, Nordrhein-Westfalen, Germany. }\end{array}$ & ZFMK & Jerman \\
\hline 11 & $\begin{array}{l}\text { Museum für Naturkunde, Leibniz-Institut für Evolutions- und } \\
\text { Biodiversitätsforschung, Berlin, Germany. }\end{array}$ & ZMB & Jerman \\
\hline 12 & $\begin{array}{l}\text { Universität Hamburg, Biozentrum Grindel und Zoologisches Museum, } \\
\text { Ichthyology, Hamburg, Germany. Usually seen as: Zoologisches Institut und } \\
\text { Zoologisches Museum der Universität Hamburg. }\end{array}$ & ZMH & Jerman \\
\hline 13 & $\begin{array}{l}\text { Zoologische Staatssammlung München, Abteilung Vertebrata, Sektion } \\
\text { Ichthyologie, München, Germany. }\end{array}$ & ZSM & Jerman \\
\hline 14 & Muséum National d'Histoire naturelle & MNHN & Perancis \\
\hline 15 & $\begin{array}{l}\text { Zoological Reference Collection, Department of Life Sciences, Faculty of } \\
\text { Science, National University of Singapore, Singapore. }\end{array}$ & ZRC & Singapura \\
\hline 16 & Personal collection of Maurice Kottelat, Carnol, Switzerland & CMK & Swiss \\
\hline 17 & $\begin{array}{l}\text { Museum d'Histoire Naturelle, Département d'Herpétologie et Ichthyologie, } \\
\text { Ville de Genève Genève Switzerland }\end{array}$ & MHNG & Swiss \\
\hline
\end{tabular}




$\begin{array}{cc}\text { NMBA } & \text { Swiss } \\ \text { BMNH } & \text { Inggris } \\ \text { NMW } & \text { Austria } \\ \text { AMNH } & \text { AS } \\ \text { ANSP } & \text { AS } \\ \text { CAS-SU } & \text { AS } \\ \text { UF } & \text { AS }\end{array}$

Florida, U.S.A.

25 Smithsonian Institution National Museum of Natural History, Department of USNM $\quad$ AS

26 Mertebrate Zioology, Division of Fishes, Washington D.C., U.S.A. (WFB)

\section{Simpulan}

Di perairan tawar P. Sulawesi telah dideskripsi 68 spesies ikan endemik dari tujuh familia, tergolong dalam empat ordo. Ke tujuh familia tersebut adalah Adrianichthyiidae (19 spesies), Telmatherinidae (16 spesies), Zenarchopteridae (15 spesies), Gobiidae (14 spesies), Anguillidae (satu spesies), Eleotridae (dua spesies), dan Terapontidae (satu spesies). Sebagian besar dari spesies endemik di P. Sulawesi hidup di perairan danau (45 spesies), 23 spesies hidup di perairan sungai. Delapan spesies ditemukan pada abad 19, sampai sebelum kemerdekaan Indonesia telah ditemukan 29 spesies, setelah merdeka ditemukan 39 spesies di P. Sulawesi. Sampai kini spesimen tipe iktiofauna dari P. Sulawesi disimpan di 27 museum dari 11 negara di dunia, terbanyak di Amerika (8), Jerman (6), Swiss (3), Australia dan Belanda (2), sedangkan di Austria, Jepang, Perancis, Singapura, Inggris, dan Indonesia masingmasing satu museum.

\section{Persantunan}

Terima kasih disampaikan kepada para peneliti yang telah melakukan penelitian di Pulau Sulawesi dan menemukan jenis-jenis endemik dan mendeposit Holotipe maupun Paratipenya di Museum Zoologicum Bogoriense (MZB), yaitu Dr. Maurice Kottelat, Dr. Lynne Parenti, Dr. Fa- bian Herder, Dr. Doug Hoese, Dr. Helen Larson, Jan Huylebrouck, dan Dr. Daniel F. Mokodongan.

\section{Daftar pustaka}

Aurich HJ. 1935a. Mitteilungen der Wallacea Expedition Woltereck. Mitteilung XIIL. Fische L Zoologischer Anzeiger 112 (5/6): 97-107.

Aurich HJ. 1935b. Mitteilungen der Wallacea Expedition Woltereck. Mitteilung XIV. Fische II. Zoologischer Anzeiger 112 $(5 / 6): 162-177$.

Aurich HJ. 1938. Die Gobiiden (Ordnung: Gobioidea). (Mitteilung XXVIII der WallaceaExpedition Woltereck.). Internationale Revue der Gesamten Hydrobiologie und Hydrographie, Leipzig 38 (1/2): 125-183.

Ahl E. 1936. Beschreibung eines neuen Fisches der Familie Atherinidae aus Celebes. Zoologischer Anzeiger 114 (7/8): 175-177

Bleeker, P. 1860. Dertiende bijdrage tot de kennis der vischfauna van Celebes (visschen van Bonthain, Badjoa, Sindjai, Lagoesi en Pompenoea). Acta Societatis Regiae Scientiarum Indo-Neêrlandicae 8 (art. 7): 1-60.

Boulenger GA. 1897. An account of the freshwater fishes collected in Celebes by Drs. P. \& F. Sarasin. Proceedings of the Zoological Society of London 1897 (2): 426429.

Brembach M. 1982. Drei neue Dermogenys-Arten aus Sulawesi: D. montanus, D. vogti, D. megarrhamphus. Die Aquarien- und 
Terrarienzeitschrift (DATZ) 35 (2): 5155.

Brembach, M. 1991. Lebendgebarende Halbschnabler- Untersuchungen zu Verbreitung, Morphologie, Systematik und Fortpflanzungsbiologie der lebendgeba halbschnabler der gattung Delmogenys und Nomorhamphus (Herrmirhamphidae: Pisces). Verlag Natur \&Wiesenschaft, Solingen.

Cerwenka AF, Wedekind JD, Hadiaty RK, Schliewen UK, Herder F. 2012. Alternative eff-feeding tactics in Telmatherina sarasinorum, a trophic specialist of Lake Matano's evolving sailfin silwersides fish radiation. Hydrobiologia 693: 131-139.

Clements R, Sodhi NS, Schilthuizen M, PKL Ng. 2006. Limestone karsts of Southeast Asia: Imperiled arks of biodiversity. Bioscience 56 (9): 733-742.

Clumsee H, Pitopang R, Mangopo H, Sabir S. 2011. Tree diversity and phytogeographical patterns of tropical high mountain rain forests in Central Sulawesi, Indonesia. Biodiversity Conservation 20: 11031123.

Collette BB. 1995. Tondanichthys kottelati, a new genus and species of freshwater halfbeak (Teleostei: Hemiramphidae) from Sulawesi. Ichthyological Exploration of Freshwaters 6(2): 171-174.

Crabbe MJC, Smith DJ. 2005. Sediment impacts on growth rates of Acropora and Porites corals from fringing reefs of Sulawesi, Indonesia. Coral Reefs 24: 437-441.

Crowe SA, O’Neill AH, Katsev S, Hehanussa P, Haffner GD, Sundby B, Mucci A, Fowle DA. 2008. The biochemistry of tropical lakes: A case study from Lake Matano, Indonesia. Limnology and Oceanography 53(1): 319-331.

Crowe SA, Katsev S, Leslie K, Sturm A, Magen C, Nomosatryo S, Pack MA, Kessler JD, Reeburg WS, Roberts JA, Gonzalez L, Haffner GD, Mucci A, Sundby B, Fowle ADA. 2011. The methane cycle in ferruginous Lake Matano. Geobiology 9: 6178 .

Cuvier G, Valenciennes A. 1837. Histoire naturelle des poissons. Tome douzième. Suite $\mathrm{du}$ livre quatorzième. Gobioïdes. Livre quinzième. Acanthoptérygiens à pecto- rales pédiculées 12: i-xxiv + 1-507 + 1 p., Pls. 344-368.

Eschmeyer WN, Fricke R, van der Laan R (eds). 2018. Catalog of Fishes : Classification. http://www.calacademy.org/scientists/cata log-of-fishes-classification/Electronic version accessed Maret 2018

Eschmeyer WN, Fong JD. 2018. Species by family/subfamily. (http://researcharchive. calacademy.org/research/ ichthyology/catalog/SpeciesByFamily.asp). Electronic version accessed Maret 2018

Froese R. and Pauly D. Editors. 2018. FishBase. World Wide Web electronic publication. www.fishbase.org, version $(02 / 2018)$

Gray SM, McKinnon JS, Tantu FY, Dill LM. 2008. Sneaky egg-eating in Telmatherina sarasinorum, an endemic fish from Sulawesi. Journal of Fish Biology 73: 728731.

Hadiaty RK. 2007. Kajian ilmiah ikan pelangi, Marosatherina ladigesi (Ahl 1936), Fauna endemik Sulawesi. Berita Biologi 8(6): 473-479.

Hadiaty RK. 2012. Ikan. In: SuhardjonoYR, Ubaidillah R (Eds.). Fauna Karst dan Gua Maros, Sulawesi Selatan. Lembaga Ilmu Pengetahuan Indonesia, Pusat Penelitian Biologi, Bogor. pp. 89-113.

Hadiaty RK, Wirjoatmodjo S. 2002. Studi pendahuluan biodiversitas dan distribusi ikan di Danau Matano, Sulawesi Selatan. Jurnal Iktiologi Indonesia 2(2): 23 -29.

Hadiaty RK, Wirjoatmodjo S, Sulistiono, Rahardjo MF. 2004. Perjalanan dan koleksi ikan di Danau Mahalona, Lantoa dan Masapi, Sulawesi Selatan. Jurnal Iktiologi Indonesia 4(1): 31-42

Haffner GD, Hehanussa PE, Hartoto DI. 2001. The biology and physical processes of large lakes of Indonesia: Lakes Matano and Towuti. The Great Lakes of the World. Food-web, Health and Integrity. Backhuys Publishers, Leiden.

Hall R. 1996. Reconstructing Cenozoic SE Asia. In: Hall R, Blundell D (Eds.). Tectonic evolution of Southeast Asia. Geological Society of London Special Publication No. 106, pp. 153-184.

Hall R. 1998. The plate techtonics of Cenozoic SE Asia and the distribution of land and sea. In: Hall R, Holloway JD (Eds.). Bi- 
ogeography and Geological Evolution of SE Asia,. Backhuys Publishers, Leiden, The Netherlands. pp. 99-131

Herder F, Nolte AW, Pfaender J, Schwarzer J, Hadiaty RK, Schliewen UK, 2006a. Adaptive radiation and hybridization in Wallace's Dreamponds: evidence from sailfin silversides in the Malili Lakes of Sulawesi. Proceeding of Royal Society B 273, 2209-2217.

Herder F, Hadiaty RK, Schliewen UK, 2006 b. Diversity and evolution of Telmatherinidae in the Malili Lakes System in Sulawesi. Proceedings of the International Symposium "The Ecology and Limnology of the Malili Lakes". Bogor, Indonesia: LIPI and PT INCO Tbk, , 67-72.

Herder F, Chapuis S 2010. Oryzias hadiatyae, a new species of ricefish (Atherinomorpha: Belonifornes: Adrianichthyidae) endemic to Lake Masapi, Central Sulawesi, Indonesia. The Raffles Bulletin of Zoology 58 (2): 269-280.

Herder F, Hadiaty RK, Nolte A. 2012. Pelvic-fin brooding in a new species of riverine ricefish (Atherinomorpha: Beloniformes: Adryanichthyidae) from Tana Toraja, Central Sulawesi, Indonesia. The Raffless Bulletin of Zoology 60(2): 267-476.

Hoese DF, Kottelat M. 2005. Bostrychus microphthalmus, a new microphthalmic cavefish from Sulawesi (Teleostei: Gobiidae). Ichthyological Exploration of Freshwaters 16 (2): 183-191.

Hoese DF, Hadiaty RK, Herder F. 2015. Review of the dwarf Gl Review of the dwarf Glossogobius lacking head pores from the Malili lakes, Sulawesi, with a discussion of the definition of the genus. The Raffless Bulletin of Zoology 63 (1): 14-26.

Holloway JD, Hall R. 1998. SE Asian geology and biogeography: an introduction. In: Hall R, Holloway JD (Eds.). Biogeography and Geological Evolution of SE Asia. Backbuys Publishers, Leiden, The Netherlands. pp. 1-23.

Huylebrouck J, Hadiaty RK, Herder F. 2012. Nomorhamphus rex, A new species of viviparous halfbeak (Atherinomorpha: Beloniformes: Zenarchopteridae) endemic to Sulawesi Selatan, Indonesia. The Raffless Bulletin of Zoology 60(2): 477-485.
Huylebrouck J, Hadiaty RK, Herder F. 2014. Two new species of viviparous halfbeak (Atherinomorpha: Beloniformes: Zenarchopteridae) endemic to Sulawesi Tenggara, Indonesia. Raffless Bulletin of Zoology 60(2): 200-209.

Kaup JJ. 1856. Catalogue of the apodal fish in the collection of the British Museum. London. 1-163, Pls. 1-19.

Kawakatsu M, Mitchell RW. 1989. Record of a troglobitic planarian from Tanette Cave located in the Maros Karst, Sulawesi (Celebes), Indonesia (Turbellaria, Tricladida, Paludicola). Bulletin Fuji Women's College 27 (2): 35-40.

Keith P, Hadiaty RK, Lord C 2012. A new species of Belobranchus (Teleostei: Gobioidei: Eleotridae) from Indonesia. Cybium 36 (3): 479-484

Keith P, Hadiaty RK, Hubert N, Busson F, Lord C. 2014. Three new species of Lentipes from Indonesia. Cybium 38(2): 133-146.

Koch A. 2011. Chapter 20: The amphibians and reptiles of Sulawesi: Underestimated diversity in a dynamic environment. In: Zachos FE, Habel JC (Eds.) Biodiversity Hotspots: Distribution and Protection of Conservation Priority Area. pp. 383-404.

Kottelat M. 1990a. Sailfin silversides (Pisces: Telmatherinidae) of Lakes Towuti, Mahalona and Wawontoa (Sulawesi, Indonesia) with descriptions of two new genera and two new species. Ichthyological Exploration of Freshwaters 1 (3): 227-246.

Kottelat M. 1990b. Synopsis of the endangered buntingi (Osteichthyes: Adrianichthyidae and Oryziidae) of Lake Poso, Central Sulawesi, Indonesia, with a new reproductive guild and descriptions of three new species. Ichthyological Exploration of Freshwaters 1 (1): 49-67.

Kottelat, M. 1990c. The ricefishes (Oryziidae) of the Malili Lakes, Sulawesi, Indonesia, with description of a new species. Ichthyological Exploration of Freshwaters 1: 151- 166.

Kottelat M. 1991. Sailfin silversides (Pisces: Telmatherinidae) of Lake Matano, Sulawesi, Indonesia, with descriptions of 6 new species. Ichthyological Exploration of Freshwaters 1 (4): 321-344. 
Ladiges W. 1972. Zwei neue Hemirhamphiden von Celebes und Cebu (Philippinen). Mitteilungen aus dem Hamburgischen Zoologischen Museum und Institut 68: 207-212, Pls. 10-11.

Lang R de, Vogel G. 2006. The snakes of Sulawesi. In: Vences M, Kohler J, Ziegler T, Bohme W (Eds.). Herpetologia Bonnensis II. Proceedings of the 13th Congress of the Societas Europaea Herpetologica. Pp. 35-38.

Larson HK. 2001. A revision of the gobiidfish genus Mugilogobius (Teleostei: Gobioidei), and its systematic placement. Records of the Western Australian Museum, Supplement No. 62. $233 \mathrm{p}$

Larson HK, Kottelat, M. 1992. A new species of Mugilogobius (Pisces: Gobiidae) from Lake Matano, central Sulawesi, Indonesia. Ichthyological Exploration of Freshwaters 3(3): 225-234

Larson HK, Geiger MF, Hadiaty RK, Herder F. 2014. Mugilogobius hitam, a new species of freshwater goby (Teleostei: Gobioidei: Gobiidae) from Lake Towuti, central Sulawesi, Indonesia. Raffles Bulletin of Zoology 62: 718-725.

Lohman DJ, de Bruyn M, Page T, Rintelen K von, Hall R, PKL Ng, Shih HT, Carvallo GR, Rintelen T von. 2011. Biogeography of the Indo-Australian Archipelago. The Annual Review of Ecology, Evolution, and Systematics 42: 205-226.

Miesen FW, Droppelmann F, Hüllen S, Hadiaty RK, Herder F. 2015. An annotated checklist of the inland fishes of Sulawesi. Bonn Zoological Bulletin 64(2): 77-106.

Meisner AD, Louie KD. 2000. Nomorhamphus kolonodalensis, a new species of viviparous halfbeak from Sulawesi (Teleostei: Hemiramphidae). Ichthyological Exploration of Freshwaters 11(4): 361-368.

Mokodongan DF, Tanaka R, Yamahira K. 2014. A new ricefish of the genus Oryzias (Belontiformes, Adrianichthyidae) from Lake Tiu Central Sulawesi, Indonesia. Copeia 2014(3): 561-567

Mokodongan DF, Montenegro J, Mochida K, Fujimoto S, Ishikawa A, Kakioka R, Yong L, Mulis, RK Hadiaty, IF Mandagi, KWA Masengi, Wachia N, Hashiguchi Y, Kitano J, Yamahira K. 2018. Phylogenomics reveals habitat-associated body shape di- vergence in Oryzias woworae species group (Teleostei: Adrianichthyidae). Molecular Phylogenetics and Evolution 118 (2018): 194-203

Moss SJ, Wilson MEJ. 1998. Biogeographic implications of the tertiary palaeogeographic evolution of Sulawesi \& Borneo. In: Hall R, Holloway JD (Eds.). Biogeography and Geological Evolution of SE Asia. pp. 133-163.

Nielsen JG, Schwarzhans W, Hadiaty RK. 2009. Ablind, new species of Diancistrus (Teleostei, Bythitidae) from three caves on $\mathrm{Mu}$ na Island, southeast of Sulawesi, Indonesia. Cybium 33(3): 241-245.

Parenti LR. 2008. A phylogenetic analysis and toxonomic revision of ricefishes, Oryzias and relatives (Beloniformes, Adrianichthyidae). Zoological Journal of the Linnean Society 154: 494-610.

Parenti LR, Louie KD. 1998. Neostethus djajaorum, new species, from Sulawesi, Indonesia, the first phallostethid fish (Teleostei: Atherinomorpha) known from east of Wallace's Line. Raffles Bulletin of Zoology 46 (1): 139-150.

Parenti LR, Soeroto B. 2004. Adrianichthys roseni and Oryzias nebulosus, two new ricefishes (Atherinomorpha: Beloniformes: Adrianichthyidae) from Lake Poso, Sulawesi, Indonesia. Ichthyological Research 51(1): 10-19.

Parenti LR, Hadiaty RK. 2010. A new, remarkably colorful, small ricefish of the genus Oryzias (Beloniformes, Adryanichthyidae) from Sulawesi, Indonesia. Copeia 2010 (2): 268-273

Parenti LR, Hadiaty RK, Lumbantobing D, Herder F. 2013. Discovery and description of two new ricefishes of the genus Oryzias (Atherinomorpha, Beloniformes, Adrianichthyidae) augments the endemic freshwater fish fauna of Southeastern Sulawesi, Indonesia. Copeia 2013(3): 403-414.

Pfaender J, Miesen FW, Hadiaty RK, Herder F. 2011. Adaptive speciation and sexual dimorphism contribute to diversity in form and function in the adaptive radiation of Lake Matano's sympatric roundfin sailfin silversides. Journal of Evolutionary Biology. Doi: 10.1111/j.1420-9101.2011. 02357 
Pfaender J, Gray SM, Rick IP, Chapuis S, Hadiaty RK, Herder F, 2014. Spectral data reveal unexpected cryptic colour polymorphism in female sailfin silverside fish from ancient Lake Matano. Hydrobiologia 739(1): 155-161.

Popta CML. 1905. Haplochilus sarasinorum, n. sp. Notes from the Leyden Museum 25 (4): 239-247.

Popta CML. 1912. Fortsetzung der Beschreibung von neuen Fischarten der Sunda-Expedition. Notes from the Leyden Museum 34 (3-4) (art. 34): 185-193.

Popta CML. 1922. Vierte und letzte Fortsetzung der Beschreibung von neuen Fischarten der Sunda-Expedition. Zoologische Mededelingen (Leiden) 7 (art. 2): 27-39.

Rintelen K von, von Rintelen T, Meixner M, Luter C, CaiY, Glaubrecht M. 2007. Freshwater shrimp-sponge association from an ancient lake. Biology letters 3: 262-264.

Rintelen T von, Glaubrecht M. 2003. New discoveries in old lakes: Three new species of Tylomelania Sarasin \& Sarasin, 1897 (Gastropoda: Cerithioidea: Pachychilidae) from the Malili Lake System on Sulawesi, Indonesia. Jurnal of Mollusc Study 69: 317.

Rintelen T von, Rintelen K von, Glaubrecht M, Schubart CD, Herder F. 2012. Aquatic biodiversity hotspots in Wallacea: the species flocks in the ancient lakes of Sulawesi, Indonesia. In: Gower DJ et al. (Eds.) Biotic Evolution and Environmental Change in Southeast Asia. pp. 290-315.

Rintelen T von, Marwoto RM, Haffner GD, Herder F. 2014. Preface: Speciation research in ancient lakes-classic concepts and new approaches. Hydrobiologia 739: 1-6.

Sabo E, Roy D, Hamilton PB, Hehanussa PE, McNeely R, Haffner GD. 2008. The plankton community of Lake Matano: McNeely factors regulating plankton composition and relative abundance in an ancient, tropical lake of Indonesia. Hydrobiologia 615: 225-235.

Schwarzer J, Herder F, Misof B, Hadiaty RK, Schliewen UK. 2008. Gene flow at the margin of Lake Matano's adaptive sailfin silverside radiation: Telmatherinidae of River Petea in Sulawesi. Hydrobiologia 615(1): 201-213.
Siebert SF. 2005. The abundance and distribution of rattan over an elevation gradient in $\mathrm{Su}-$ lawesi, Indonesia. Forest ecology and Management 210: 143-158.

Stelbrink B, Stöger I, Hadiaty RK, Schliewen UK, Herder F, 2014. Age estimates for an adaptive lake fish radiation, its mitochondrial introgression, and an unexpected sister group: Sailfin silversides of the Malili Lakes system in Sulawesi. BMC Evolutionary Biology 2014, 14.94. http: //www.biomedcentral.com/1471$2148 / 14 / 94$

van der Laan R, Eschmeyer WN, Fricke R. 2018. Family-group names (http://www.calacademy.org/scientists/catalog-of-fishesfamily-group-names). Electronic version accessed Maret 2018.

Vari R, Hadiaty RK. 2012. The endemic Sulawesi fish genus Lagusia (Teleostei: Terapontidae). The Raffless Bulletin of Zoology 60 (1):121-126.

Vogt D. 1978. Kennen sie Nomorhamphus? Eine Übersicht und vorläufige Beschreibungen einer neuen Unterart, nämlich Nomorhamphus liemi snijdersi und einer Art, nämlich Nomorhamphus brembachi. Die Aquarien- und Terrarienzeitschrift (DATZ) 31 (7): 222-227.

Voris HK. 2000. Maps of Pleistocene sea levels in Southeast Asia: shorelines, river systems and time durations. Journal of Biogeography 17: 1153-1167

Weber, M. 1894. Die Süsswasser-Fische des Indischen Archipels, nebst Bemerkungen über den Ursprung der Fauna von Celebes. Zoologische Ergebnisse einer Reise in Niederländisch Ost-Indien 3 (2): 405476.

Weber M. 1913. Neue Beiträge zur Kenntnis der Süsswasserfische von Celebes. Bijdragen tot de Dierkunde 1913: 197-213.

Weber M, de Beaufort LF. 1922. The fishes of the Indo-Australian archipelago. IV. Heteronomi, Solenichthyes, Synentognathi, Percesoces, Labyrinthici, Microcyprini. Brill, Leiden.

Whitten TJ, Henderson GS, Mustafa M. 2012. Ekologi Sulawesi. Penerjemah: Tjitrosoepomo, Gadjah Mada University Press. Yogyakarta. 
Wirjoatmodjo S, Rahardjo MF, Sulistiono, Suwelo IS, Hadiaty RK. 2003. Ecological distribution of endemic fish species in Lakes Poso and Malili Complex, Sulawesi Island. Final Report of ARCBC Project.

Yamahira K, Mochida K, Fujimoto S, DF Mokodongan, Montenegro J, Kaito T, Ishikawa A, Kitano J, Sue T, Mulis, Hadiaty RK, Mandagi IF, Masengi KWA. 2016. New localities of the Oryzias woworae species group (Adrianichthyidae) in Sulawesi Tenggara. Jurnal Iktiologi Indonesia 16(2): 125-131.

Zitzler K, Cai Y. 2006. Caridina spongicola, new species, a freshwater shrimp (Crustacea: Decapoda: Atyidae) from the ancient Malili Lake System of Sulawesi, Indonesia. The Raffless Bulletin of Zoology 54(2): 271-276. 